Teaching \& Learning (2012) 7(2), 28-40

\title{
Engaging Difference and Racial Equity: What School Leaders Need to Know and Do
}

\author{
KATLYN DAVIS \\ Brock University \\ DENISE E. ARMSTRONG \\ Brock University
}

\begin{abstract}
This article explores the role of school leaders in effecting equity in schools and promoting the success of racialized students. While a review of the literature identifies a positive correlation between educators' understanding of racial issues and their effective engagement in promoting equitable practices within their schools, teachers and administrators are seldom prepared to work effectively with students, families, and communities from different ethno-racial backgrounds. This paper discusses fundamental concepts school leaders should know, as well as approaches and strategies they can adopt, in order to move towards achieving equity for racialized populations. Equipped with relevant knowledge, approaches, and strategies, school leaders will be better able to address inequitable practices, while proactively supporting socially just practices that ensure success for all students.
\end{abstract}

\section{Introduction}

This article explores the role of school leaders in effecting equity in schools and promoting the success of racialized students. In Ontario and other jurisdictions, educators' legal and moral responsibility to care for and support all students, is enshrined in their professional codes, legal statutes, and in provincial and federal policies (e.g., see http://www.oct.ca/public/professional-standards/ethical-standards). As a result, teachers and administrators are uniquely placed to create schools where all students have equitable educational opportunities and racialized students (i.e., students who are viewed as other than White) are equally successful (Jean-Marie, Normore, \& Brooks, 2009). School leaders' formal roles also allow them to influence areas such as decision-making, policy development, and vision setting (Evans, 2001). However, in spite of school leaders' access to power and their articulated commitments to racial equity, research conducted in Ontario and abroad, consistently shows that racialized minorities do not have the same levels of access or success as their White peers. For the most part, this research reveals disturbing patterns, particularly for Aboriginal and Black 
students. These include lower teacher expectations and academic scores, as well as disproportionate and higher rates of streaming into vocational programs, academic failure, suspension, and expulsion (e.g., see Carr \& Lund, 2009; Dei, 2007; McMahon \& Armstrong, 2010; Ryan, 2012; Solomon, 2002).

A large number of studies also examine the successes and failures of school leaders as they seek to address structures and processes that impact cultural and racial difference in their schools (McMahon \& Armstrong, 2010; Ryan, 2012). Related to this, many researchers consider the connection between school leaders' knowledge of racial issues, and their ability to enact strategies and promote racial equity in schools (e.g., see Alsbury and Whitaker, 2006; Carr and Lund, 2009; Evans, 2007; McMahon, 2007; Ryan, 2003; Solomon, 2002). For the most part, this research shows that school leaders are unprepared for the challenges of achieving racial equity, and are uncomfortable naming race and racism (Aveling, 2007; McMahon, 2007; Ryan, 2012). Within this framework of understanding that school leaders can and should act as equitable and moral change agents, we discuss what educators need to know and do, in order to transform individual and organizational equity ideals and goals into action. Using the literature as a guide, this article outlines fundamental concepts and strategies that facilitate school leaders' engagement in racial equity work in their schools.

\section{School Leaders' (Mis)understandings of Race and Racism}

School leaders' understandings of, and approaches for, dealing with issues of race and racism, impact their ability to effectively address and promote racial equity within their schools (Evans, 2007; Henze, Katz, \& Norte, 2000; McMahon, 2007; Ryan, 2003; Solomon, 2003). In spite of good intentions and articulated commitments to inclusion, many misunderstandings exist, allowing racism and racial inequity to go unnoticed and/or unaddressed in schools. Many school leaders do not perceive racism as a problem in schools. If they do see racism in their schools, they tend to downplay its significance, and to identify racial occurrences as isolated individual behaviours that are due to stereotyping and prejudicial attitudes, as opposed to systemic structures and practices (Aveling, 2007; McMahon, 2007; Ryan, 2003, 2012). An analysis of Canadian schools, conducted by Henry, Tator, Mattis, and Rees (2000), identifies varying discourses that limit educators' understanding and recognition of racism in schools, which, for the most part, exist to deny or ignore racism. These discourses include: denial of the 
problem; colour blindness (claiming not to see race, but seeing and treating everyone as equal); decontextualization (blaming the victim and attributing failure to deficits inherent within racialized students and their families); and political correctness (refusal to name race).

School leaders' understandings of race and racism may also be connected with the ways in which they do (or do not) approach and address issues of social justice in schools. McMahon's (2007) study of White administrators in Ontario, found that school administrators had limited views of how equity and social justice could be applied to dealing with racism in schools. For the most part, social justice was seen as developing remedial programs with the goal of equitable outcomes or helping disadvantaged people outside of the school community. Alsbury and Whitaker (2006) also found that leaders most often equated social justice with "doing what's best for the student" (p. 166) without knowing what this entailed. Similarly, McMahon (2007), Solomon (2002), and Ryan (2003) found leaders had varying views of what an antiracist approach to education involved, and how it could be integrated in their schools. Often antiracism was associated with initiatives that prevent and address individual acts of racism (McMahon, 2007), and was equated with multiculturalism (Solomon, 2002). With an incomplete understanding of equity-based approaches, school leaders lack a systemic approach, restricting their ability to address systemic and societal barriers. As a result, the problems racialized students face often remain intact and without challenge. For educators to effectively engage difference and racial equity, they must understand that racism needs to be addressed not only on the level of the individual, but also on systemic and societal levels.

Educators must acknowledge and understand difference, in order to effectively deal with racism (Evans, 2007; Henze, Katz, \& Norte, 2000). Evans (2007) suggests that developing a comprehensive knowledge base is important for school leaders, because they make decisions and respond to situations related to race in ways that reflect their sensemaking of racial issues. Evans (2007) further suggests that without an in-depth understanding of racial issues, educators will not have a realistic view of the challenges racialized students face, and will be unable to recognize, challenge, and change oppressive structures and practices in their schools. This is particularly important for formal organizational leaders (e.g., principals, supervisory officers, directors), and also for teachers. Ryan (2003) argues that it is important for school leaders to have an understanding of racial issues, because they have the power to influence racist and antiracist practices in their schools. More specifically, school leaders will not recognize the need for action 
on their part, without an understanding of their power and moral responsibility to institute racial equity in their schools, and this gap in knowledge has been identified in many school leaders. In reality, many school leaders lack the knowledge of racial issues and appropriate strategies for dealing with racism in schools (Evans, 2007; Marshall \& Ward, 2003; McMahon, 2007; Ryan, 2003; Solomon, 2002). Addressing this gap in knowledge about racial equity, as well as individual and organizational responsibility, is a first step in moving schools towards more equitable practices, and ultimately ensuring academic and personal success for racialized students.

\section{What School Leaders Need to Know}

Our review of the literature identified basic knowledge that school leaders need to develop, in order to effectively engage in racial equity work in their schools. Foremost among these are learning that racism occurs at the individual, systemic, and societal levels, and it is enacted in covert and overt ways. Knowledge of the dynamics of racism, their own racial location, and how it intersects with other areas of difference, can provide school leaders with dispositions and tools to analyze the attitudes, procedures, and practices in their schools, and create more equitable educational communities.

\section{Understanding Racism}

In order to ensure success for racialized students, leaders need to understand that power, privilege, prejudice, and discrimination are at the core of racism, and that it is prevalent in individual attitudes, as well as school, societal, and cultural practices and procedures. Individuals need to recognize that racist attitudes are not inherent, but developed over time through socialization (Adams, Bell, \& Griffin, 2007). These assumptions and beliefs operate at the subconscious level and are often invisible (Adams et al., 2007; Shields, 2004). Racism in Ontario schools often goes unnoticed, because of the culture of power that normalizes and privileges Whiteness and Eurocentric cultural norms (Ryan, 2012). Okun (2010) points out that we often do not notice White culture as dominant, and when noticed, "we tend to assume its inevitability; we see it as 'natural' rather than constructed" (p. 5). Kivel (2002) further explains that because people who are seen as White have always lived in a culture where they have had privilege, they are slow to notice when another group is treated differently. In this sense, racism 
is systemic; White culture is normalized and favoured within our society, and it dictates the values and beliefs upon which our social systems are built. As a result, leaders need to develop knowledge about how to change racist norms, and act on this knowledge, or racism will continue indefinitely.

Racism pervades all levels of the education system, but is most evident at the elementary and secondary school level (Ryan, 2003). Before school leaders can promote racial equity in their schools, they must recognize that schools are a microcosm of society that replicate and reproduce dominant values, beliefs and assumptions through formal and informal authority, and curricular structures and processes. They must also understand how racist practices and ideologies impact racialized students and their communities, how dominant groups benefit from marginalizing racialized minorities, and how well-meaning educators inadvertently perpetuate these inequities.

Racism in schools is complex and manifested in various forms, appearing as "obvious and not so obvious guises - in the name-calling, harassment and the interpersonal conflict, in the subtle stereotyping and taken for granted understandings and practices and in curricular and organizational patterns" (Ryan, 2003, p. 62). In a study of Canadian schools, Carr and Lund (2009) found that while individual acts of racism, such as name calling and harassment are widely condemned, systemic racism (i.e., endemic structures and practices such as hiring, streaming, and stereotypes in the education system that disadvantage racialized students) is still a reality. Henry et al. (2000) presented an analysis of systematic racism that also shows the needs and experiences of racialized students are not reflected in the formal curriculum (e.g., textbooks), and hidden curriculum (i.e., pedagogy, assessment, and streaming). Furthermore, Henry et al. (2000) identify other systemic manifestations of racism in the educational system, including racially biased attitudes and practices of teachers and administrators, the assimilationist culture of school, lack of representation of racialized students in teaching and administrative staff, and devaluing the role and participation of parents and the community.

Racism in schools is detrimental to racialized students, often preventing their success in school and beyond. Discriminatory and oppressive structures, practices, stereotypes and individual acts, are issues racialized students encounter throughout their education (Dei, 2007; Henry et al., 2000; McMahon, 2007; Ryan, 2003). Many students struggle in schools because their experiences and communities' positive achievements are not reflected in the formal 
curriculum (Henry et al., 2000). Dei (2007) reports high levels of drop out or push out for Aboriginal and Black students who become disconnected and disengaged, due to marginalizing curricular practices, low expectations, and unfair disciplinary practices. These educational experiences not only impact how students identify themselves (Carr \& Lund, 2009), but they carry serious individual and societal consequences. For racialized students, consequences include higher incarcerations and dropout rates, limited access to post secondary education, as well as economic and job opportunities (Solomon, 2006). Racism also has a high cost for those who are privileged based on their racial identification. Kivel (2002) shows racism in schools may lead to ignorance, misinformation, scapegoating, blaming, labeling, self-righteous anger, a sense of entitlement, and individualism. Finally, the greatest cost of not addressing racism in schools is that, without action, it will replicate itself and continue indefinitely.

\section{Understanding Self}

Many authors suggest that before school leaders can identify and address racist practices in their schools, they must first have a better understanding of themselves and their own racial location and identity (Carr \& Lund, 2009; Evans, 2007; Solomon, 2002; Theoharis \& Haddix, 2011). More specifically, racial identity plays an important part in how school leaders engage difference and racial equity, and how they "see themselves and interpret, make sense of, and treat others" (Evans, 2007, p. 185). Identity can affect leaders' attitudes and behaviours, and as a result, may dictate their ability to confront old organization ideologies and develop new ideologies that are more inclusive (Carr \& Lund, 2009; Evans, 2007). In order to uncover and change racist attitudes, individuals must go through many stages of self-awareness. These include confronting the moral dilemmas of racism, and moving past the desire to preserve unearned privilege (Helms, 1990). Helms suggests that individuals do not begin the process of restructuring their emotional and cognitive orientation towards racism, until they become uncomfortable with their racist behavior.

Discomfort with racism, and an awareness of how their own characteristics, privilege, knowledge, and beliefs help or hinder their ability to create inclusive schools, can help educators determine effective steps to evaluate their role in the process, and engage themselves and others in developing more equitable schools. While school leaders are undoubtedly in a position to influence change and promote equity within schools, and while they may understand their moral 
and legal responsibilities, racialized students will not benefit unless educators take action. Brooks and Tooms (2008) stress it is not enough to know something needs to be done. They challenge leaders to "eschew complacency and instead embrace, as necessary, a reflective, action-oriented, intentional, and synergistic advocacy" (p. 158).

\section{Understanding Equity-Based Approaches}

Our review of the literature confirms that because racism is complex and multifaceted, educators may need to employ multiple approaches, in order to address inequities. While interventive responses may sometimes be required to deal with racist incidents and conflicts, preventative approaches adopted in the short, medium, and long-term, may ensure equity of access and opportunity. These proactive approaches that address racial inequities, such as social justice, antiracism, and critical multiculturalism, may support school leaders in addressing racism (Aveling, 2007; Dei, 2007; Ryan, 2012). Ryan and Rottman (2007) summarize key assumptions of a critical approach to social justice in education, as including favoring equity over equality, involving all aspects of education, moving beyond resource distribution to recognition of discrimination, and acting with hope. Similarly, anti-racism is a practice-based approach which integrates multiple voices and perspectives into curriculum, school policies, and school procedures, using a critical humanist perspective that focuses on participants assuming responsibility for the change of inequitable social structures (McMahon, 2007). In contrast, critical multiculturalism places emphasis on the ways in which culture and power are related, historical contexts, and the need for personal and social transformation (Kincheloe \& Steinberg, 1997).

While these equity-based approaches vary in terms of their philosophical underpinnings, they are based on the general premise that social structures that are built on unequal power relations create inequities (McMahon, 2007). Educators are more likely to favour a broad social justice approach, because it provides a wide scope of study and practice which acknowledges the intersections between different forms of oppression (McMahon \& Armstrong, 2010; Ryan \& Rottman, 2007), in which educators can interrogate unequal relationships of power, and eliminate individual, systemic, and societal practices that marginalize and oppress others. 


\section{What Leaders Need to Do}

With a fundamental understanding of racism and its impact in the context of schools, school leaders can begin to conceptualize what they should do to engage racialized groups. While knowledge is important, operationalizing their good intentions can be a struggle (Ryan, 2012). Educators may well ask, "How can we move from awareness to action?" In the next section, we suggest core strategies and approaches school leaders and communities can use to identify racist practices, and ensure equitable schools.

\section{Assessing Racism in Schools}

One method school leaders could use to evaluate their schools for racism, is to collect qualitative and quantitative data, through environmental scans or equity audits. Equity audits indicate areas in which administrators may need to increase their knowledge and develop appropriate strategies (Skrla, Scheurich, Garcia, \& Nolly, 2010). Schools and school boards can systematically and objectively use them to determine equitable practices, specifically in the areas of teacher quality, programming (such as special education, gifted education, and student discipline), and student achievement (Skrla et al., 2010). Groenke (2010) identifies specific indicators of racism that leaders can use to determine which practices and procedures disadvantage racialized students. For example, Groenke suggests measuring discipline data by considering how many students were frequently truant, suspended, expelled, or placed in an alternative school setting, in the last year. This data would then be disaggregated by race.

While equity audits often provide quantitative methods to evaluate schools, many simple qualitative methods for evaluation are available. Dismantling Racism Works (an organization that develops resources and facilitates workshops aimed at addressing racism in organizations) provides an assessment for organizations, which asks thought provoking questions and could be appropriately used by individuals and/or communities to evaluate schools (see http://www.westernstatescenter.org/tools-and-resources/Tools/Dismantling\%20Racism). This assessment considers areas such as decision-making, financial resources, organizational culture, and partnerships, to determine how racial equity can be achieved. Similarly, some school boards and ministries of education have designed their own assessments related to anti-racism policies. For example, York Region District School Board and the Ontario Ministry of Education have developed their own list of indicators to evaluate their schools (see 
www.yrdsb.edu.on.ca/pdfs/a/depts/racerel/Antiracism Indicators.pdf and

http://www.edu.gov.on.ca/eng/document/curricul/antiraci/antire.pdf).

Finally, SWOT analyses (strengths, weaknesses, opportunities, threats) can be useful tools to assess specific situations, strategies, or schools for strong and weak areas as needed. While this tool was originally developed for assessing business processes, it can be easily adapted to education contexts (see http://www.businessballs.com/free_SWOT_analysis_template.pdf for a template).

\section{Engaging Schools and Communities}

Using qualitative and quantitative data and their moral compass as a guide, educators could work with others inside and outside of schools to create specific goals and timelines regarding what they hope to accomplish. By engaging school community members in the change process, school leaders build consensus and secure allies (Dufour, Dufour, Eaker, \& Many, 2006). While planning and decision making processes are often restricted to teachers and administrators or selected committees in the school, authentic and inclusive consultation with members at all levels of the school community including students, parents, staff, teachers, administrators, etc., ensure that changes will be more accepted and implemented by the school community when they have a genuine part of the reform process (e.g., deciding what types of reform to implement, as well as how implementation will take place) (Datnow, 2000).

Respectful dialogue and critical reflection are proactive ways to engage racialized communities, address racial issues, and build strong working relationships (Armstrong \& McMahon, 2004; Shields, 2004). Reciprocal dialogue begins the process of overcoming silence related to racism, challenges existing beliefs about racism and racist practices, and ensures that all voices are heard. It can also help individuals identify the range of racial identities that exist (Carr \& Lund, 2009). Broad-based consultations that are geared towards accomplishing mutually developed goals, and creating specific plans and timelines for the implementation of these goals, are proactive ways to develop inclusive and sustainable schools (McMahon \& Armstrong, 2004). Though initially uncomfortable, discussing racial issues individually and in groups with school community members, can also deepen educators' perspectives, increase trust, and build powerful coalitions for change. 
Reflection does not always occur naturally, and therefore it is important that educators commit to engaging in critical reflection, and making it a routine practice. Ryan (2003) suggests that reflection can be used by school leaders, to evaluate the ideas, practices, and situations in their schools, with their equity goals in mind. It will cause school leaders to step back from the patterns present in schools, and problematize issues that disadvantage students. When critical reflection is integrated into the process of individual and community learning, it can enhance community dialogue, build trust, and create a culture that naturally engages equity and difference (Shields, 2004). Critical reflection asks questions such as: Who benefits and who is disadvantaged by normalized structures and processes within schools (e.g., policies and procedures, curriculum, pedagogical practices, streaming, etc.)? This increased consciousness may also help school leaders develop action plans, as they increase their engagement toward equitable practices (Solomon, 2002). As part of critical and respectful dialogue, school leaders and community members can also reflect on questions such as: What do we want to achieve in our schools? Where do we want our school to be in six months, one year, and two years? What are the factors and processes that (dis)engage racialized students, parents, and guardians? How are we complicit in these dynamics? Which structures and processes do we need to put in place to support racialized students? It is important that the solutions developed, place students' needs at the centre, and include agreed upon indicators, outcomes, and timelines that are integrated within the larger school improvement plans. Finally, when implementing equity goals and plans, educational communities need to purposefully set time aside to assess how plans are working, identify challenges and promising practices, make the necessary modifications, and celebrate successes with their communities (Evans, 2001).

\section{Addressing Barriers to Racial Equity}

In the case of moving towards racial equity in schools, school leaders will face obstacles specifically related to racism, since this will require deep changes in administrative and teaching practices, authority structures, school procedures, and curriculum in attitude and practice (Evans, 2001). To overcome these barriers and move towards engaging difference and promoting racial equity, school leaders need to create an atmosphere where changes can be facilitated, and those implementing the changes (e.g., the staff, students, parents, and greater school community) are engaged in the process (their voices are heard) and supported (given necessary resources and 
training) throughout the transition period. Engaging this process will include the facilitation of professional learning in relation to racism, including the school community in the change processes, and the effective modeling of equitable practices.

The use of knowledge sharing as a key component in successful change (Dufour, Dufour, Eaker, \& Many, 2006), is a strategy that allows the school community members to be part of the change process. Only then will change seem desirable and feasible, because it will allow those involved to understand the situation (Evans, 2001). As well, when school community members are provided with the opportunity to gain knowledge about racial inequities and strategies for restructuring the community, they will be able to engage in the process and provide valuable input, as to what goals should be set and how they can be achieved.

Finally, it is essential that school leaders model the change they want to see. Aligning with Evans' (2001) statement that "example is still the most powerful teacher" (p. 21), when school leaders model equitable behaviours and practices, those in the school community will have a better understanding of what racial equity looks like in practice, and will be more likely to display similar behaviours.

\section{Conclusion}

School leaders have a significant amount of influence within schools, because they affect the day to day actions of teachers and students. They are also legally and morally accountable to address unethical practices in schools, and to provide conditions and processes that include all students (Ryan, 2003; Starratt, 2009). In the context of racial equity, they can make changes to ensure racialized students achieve academic and non-academic success. Jean-Marie, Normore, and Brooks (2009), speak to the role of schools leaders in engaging equity: "School leaders are potentially the architects and builders of a new social order wherein traditionally disadvantaged peoples have the same educational opportunities, and by extension social opportunities, as traditionally advantaged people" (p. 4). Making a change towards racial equity in schools is challenging, but possible. School leaders have unique opportunities to influence and engage school communities in equity work, and they should be supported in this process by their districts and each other. When school leaders have knowledge of racism and how it affects their students and schools, and are equipped with strategies, they will be able to identify and address practices that disadvantage racialized students. With this understanding, educating school leaders 
is necessary. Topics related to equity, racism, anti-racism, and social justice should be embedded in school professional development initiatives, teacher and administrator preparation programs, and graduate studies programs, so school leaders will be prepared to promote equity in their schools. Without a fundamental understanding of the issues at play in our education system and strategies to use in their schools, leaders will not be able to effectively engage equity and build socially just schools.

Katlyn Davis earned her Bachelor's Degree in Science (biomedical biology) and Bachelor of Education from Laurentian University, and recently completed the Master of Education program at Brock University in Administration and Leadership. For her masters research project she developed a workshop designed to increase school administrators' understanding related to racial issues in their schools. Currently, Katlyn is a Learning Strategist at Redeemer University College and continues to actively pursue varying research opportunities.

Denise E. Armstrong is an Associate Professor, Administration and Leadership, in the Faculty of Education at Brock University, and she has worked in a variety of academic and administrative roles in K-20 institutions in Canada and the Caribbean. Her writing and research focus on ethical leadership, social justice, and antiracist pedagogy and she is the author of "Administrative Passages: Navigating the Transition from Teacher to Assistant Principal" and co-author of "Inclusion in Urban Educational Environments: Addressing Issues of Diversity, Equity and Social Justice".

\section{References}

Adams, M., Bell, L., \& Griffin, P. (Eds.). (2007). Teaching for diversity and social justice (2 ${ }^{\text {nd }}$ ed.). New York, NY: Routledge.

Alsbury, T., \& Whitaker, K. (2006). Superintendent perspectives and practice of accountability, democratic voice and social justice. Journal of Educational Administration, 45(2), 154174. doi:10.1108/09578230710732943

Aveling, N. (2007). Anti-racism in schools: A question of leadership? Discourse: Studies in the Cultural Politics of Education, 28(10), 69-85. doi: 10.1080/01596300601073630

Brooks, J. S., \& Tooms, A. K. (2008). A dialectic of social justice: Finding synergy between life and work through reflection and dialogue. Journal of School Leadership, 18, 134-163.

Carr, P. R., \& Lund, D. E. (2009). The unspoken color of diversity: Whiteness, privilege, and critical engagement in education. In S.R. Steinberg (Ed.), Diversity and multiculturalism (pp. 45-55). New York, NY: Peter Lang.

Datnow, A. (2000). Power and politics in the adoptions of school reform. Educational Evaluation and Policy Analysis, 22(4), 357-374.

Dei, G. (2007). Schooling as community: Race, schooling, and the education of African youth. Journal of Black Studies, 38(3), 346-366. doi: 10.1177/0021934707306570

DuFour, R., DuFour, R., Eaker, R., \& Many, T. (2006). Learning by doing: A handbook for professional learning communities at work. Bloomington, IN: Solution Tree. 
Evans, A. (2007). School leaders and their sensemaking: About race and demographic change. Educational Administration Quarterly, 43(2), 159-188. doi:10.1177/0013161X06294575

Evans, R. (2001). The human side of school change: Reform, resistance, and the real-life problems of innovation. San Francisco, CA: Jossey-Bass.

Groenke, S. L. (2010). Seeing, inquiring, witnessing: Using the equity audit in practitioner inquiry to rethink inequity in public schools. English Education, 43(1), 83-96.

Helms, J. E. (1990). Black and white racial identity: Theory, research and practice. Westport, CT: Praeger.

Henry, F., Tator, C., Mattis, W., \& Rees, T. (2000). Racism in Canadian Education. In F. Henry \& C. Tator (Eds.), The colour of democracy: Racism in Canadian society ( $2^{\text {nd }}$ ed.) (pp. 251-261). New York, NY: Harcourt Canada.

Henze, R., Katz, A., \& Norte, E. (2000). Rethinking the concept of racial or ethnic conflict in schools: A leadership perspective. Race Ethnicity and Education, 3(2), 195-206.

Jean-Marie, G., Normore, A. H., \& Brooks, J. S. (2009). Leadership for social justice: Preparing $21^{\text {st }}$ century school leaders for a new social order. Journal of Research on Leadership Education, 4(1), 1-31.

Kincheloe, J., \& Steinberg, S. (1997). Changing multiculturalism. Philadelphia, PA: Open University Press.

Kivel, P. (2002). Uprooting racism: How white people can work for racial justice. Gabriola Island, BC: New Society Publishers.

Marshall, C., \& Ward, M. (2004). "Yes, but...": Education leaders discuss social justice. Journal of School Leadership, 14, 530-563.

McMahon, B. (2007). Educational administrators' conceptions of whiteness, anti-racism and social justice. Journal of Educational Administration, 45(6), 684-696. doi:10.1108/09578230710829874

McMahon, B., \& Armstrong, D. (2010). Unraveling the knots and strengthening the ties: Countering democratic racism. International Journal of Urban Educational Leadership, 4(1), 160-172.

Okun, T. (2010). The emperor has no clothes: Teaching about race and racism to people who don't want to know. Charlotte, NC: Information Age.

Ryan, J. (2003). Leading diverse schools. Dordrecht, NE: Kluwer Academic.

Ryan, J. (2012). Struggling for inclusion: Educational leadership in neoliberal times. Greenwich, CT: Information Age Publishing.

Ryan, J., \& Rottman, C. (2007). Educational leadership and policy approaches to critical social justice. Journal of Educational Administration and Foundation, 18(1), 9-23.

Shields, C. (2004). Dialogic leadership for social justice: Overcoming pathologies of silence. Educational Administration Quarterly, 40(1), 109-132. doi:10.1177/0013161X03258963

Skrla, L., Scheurich, J. J., Garcia, J., \& Nolly, G. (2010). In C. Marshall \& M. Oliva (Eds.), Leadership for social justice ( $2^{\text {nd }}$ ed.) (pp. 259-283). Boston, MA: Pearson.

Solomon, R. P. (2002). School leaders and antiracism: Overcoming pedagogical and political obstacles. Journal of School Leadership, 12, 174-197. doi:1052-6846/02/02 0174-24

Starratt, R. J. (2009). Ethical leadership. In B. Davies (Ed.), The essentials of school leadership $\left(2^{\text {nd }}\right.$ ed.) (pp. 74-90). London, UK: Sage.

Theoharis, G., \& Haddix, M. (2011). Undermining racism and a whiteness ideology: White principals living a commitment to equitable and excellent schools. Urban Education, 46(6), 1332-1351. doi:10.1177/0042085911416012 